\title{
Formulation and Quality Optimization of Effervescent Tablet of Glipizide: An Approach to Comfort Anti-Diabetic Medication
}

\author{
Aklima ${ }^{1}$, Prodip Kumar Baral ${ }^{1}$, Mohammad Tohidul Amin ${ }^{1}$, Tariqul Islam Emon ${ }^{1} \&$ Mohammad Salim Hossain $^{1}$ \\ ${ }^{1}$ Department of Pharmacy, Noakhali Science and Technology University, Noakhali 3814, Bangladesh \\ Correspondence: Prodip Kumar Baral \& Mohammad Salim Hossain, Department of Pharmacy, Noakhali Science \\ and Technology University, Noakhali 3814, Bangladesh. Tel: 88-0173-568-8790.
}

Received: November 6, 2020; Accepted: November 30, 2020; Published: December 7, 2020

\begin{abstract}
The present study is targeted to formulate and prepare effervescent tablets of Glipizide to provide more elegancy, comfortability, and improved pharmacokinetics in diabetic treatment than the conventional dosage. Three formulations (F1, F2, and F3) of the effervescent tablet of Glipizide (5mg) were formulated with different amounts and ratios of excipients. By wet granulation technique, 60 tablets for every formulation were prepared with a weight of $700 \mathrm{mg}$ per tablet. Then, the features of both granules and tablets were evaluated by published methods. The angle of repose, Hausner ratio, Carr's index, Loss on drying (LOD), and Moisture Content (MC) used to measure granules property successfully proved right follow ability and compressibility. In contrast, physical and drug content related investigation failed to determine the perfectness of all three formulations. Friability on the formulations was around $0.70 \%$, indicating the expected USP limit of friability ( 0.5 to $1 \%$ ). The mean disintegration time of the formulations was from 95 s to 105 s. The tablet potency assay found $95.20 \%$ for $\mathrm{F} 1,88.80 \%$ for $\mathrm{F} 2$, and $97.40 \%$ for $\mathrm{F} 3$. The dissolution pattern of the drug followed a linear relationship with time. After one and a half hours, the highest amount of $59.20 \%$ cumulative dissolution was determined for F3 that revealed its strategic improvement of the drug solubility. As Glipizide is a poorly water-soluble drug, the effervescent tablet might mitigate disintegration and dissolution-related limitations and, consequently, enhance the drug's bioavailability.
\end{abstract}

Keywords: anti-diabetic, dissolution, drug solubility, flow property, granulation

\section{Introduction}

Effervescent tablets offer both qualities of solid and liquid dosage forms. The tablets are dispersed and dissolved in water and administrate as a liquid. It presents the drug as a palatable liquid form; nevertheless, it retains the advantage of a solid dosage form such as dose accuracy, long stability, and easy portability (Khan et al., 2014; Mohammed et al., 2016). This dosage form is becoming increasingly popular due to the ease of consumption. The buoyant delivery system is designed to break in contact with water, often causing the tablet into an effervescent solution (Agyilirah et al., 1991; Saleh SI et al., 1988). However, the dosage types face many important parameters during manufacturing and storage. Due to premature effervescent reaction, Effervescent tablets are sensitive to chemical stability. The ingredients used are extensively hygroscopic. Furthermore, the presence of a trace amount of water commences to a self-propagating reaction and continues until a complete deterioration of the product's quality (Harald, 2003). So, the preparation procedures should be carried out in a controlled environment for humidity and temperature (Khan et al., 2014; Josep et al., 2011; Osei-Yeboah et al., 2014).

Glipizide, a second-generation anti-diabetic drug under sulfonylurea class, is used to treat type II diabetes (Patel et al., 2005). Patients with type II diabetes have multiple defects like excessive hepatic glucose production, inadequate insulin secretion, and insulin resistance, leading to mild to severe hyperglycemia (Nauck et al., 2007). Glipizide depolarizes pancreatic beta cells by partially blocking the potassium channels of the cells of islets of Langerhans, which results in the voltage-gated calcium channels' opening and consequently enhances the calcium influx into the cells (Abdelmoneim AS et al. 2012). The influx encourages beta cells to release insulin (Bösenberg and Van Zyl, 2008). According to the Biopharmaceutics Classification System (BCS), Glipizide is a Class II drug that means its limitation of absorption is limited by dissolution in the gastrointestinal tube, and thus in vivo oral absorption and bioavailability (Jamzad and Fassihi, 2006; Verma RK. and Garg S. 2005; Tsume Y et al., 2012). Earlier studies indicate the facilitation of in vitro and thus oral bioavailability in vivo Glipizide by various techniques, including reducing particles, strong dispersion, and cyclodextrin complexation (Agrawal AG et al., 
2015 and Isaac J et al. 2013). Patients treated with the drug are suggested to take one or two doses daily, and the recommended maximum amount is up to $20 \mathrm{mg}$ (Östman et al., 1982). Again, Clinical studies have shown that the absorption of Glipizide in vivo is dependent on the formulation.

Diabetes is a chronic disease, so its treatment pattern and medication should be comfortable and elegant with daily lifestyle. Furthermore, Solid dosage forms are not always swallowable for geriatric and pediatric patients (Lieberman et al., 2009). For bed-restricted patients, the problem seems more severe (Aslani and Jahangiri, 2013). The formulation development study targeted to minimize the limitations of drug dissolution in gastrointestinal tracts and make an elegant dosage form to adhere to the patients for better patient compliance and bioavailability profile during the prolonged anti-diabetic medication.

\section{Materials and Methods}

a. Chemicals and reagents:

Glipizide (gift sample from Beximco Pharma Ltd., Bangladesh), Polyvinylpyrrolidone K30 (Merck, Germany), Corn Starch (Merck, India), Sodium bicarbonate (LOBA Chemie, India), Citric acid, Ascorbic acid (Merck, India), Sodium Saccharine (HCT, China), Lactose (BDH, England), Magnesium stearate (Merck, Germany), Sodium Metabisulphite (Merck, India), Congo red (BDH, England). All the reagents were purchased through RFQ from local Suppliers.

\section{b. Tablet formulation}

Three formulations of Glipizide 5mg tablet named F1, F2, and F3 were calculated with different proportions of excipients and made a total of $700 \mathrm{mg}$ weight, as described in Table-1. The formulation study was conducted in the Pharmaceutical Technology Laboratory at the Department of Pharmacy, Noakhali Science and Technology University.

Table 1. Formulations of Glipizide $5 \mathrm{mg}$ Effervescent tablet.

\begin{tabular}{llll}
\hline Ingredients & \multicolumn{3}{l}{ Formulations } \\
\cline { 2 - 4 } & F1(mg) & F2 (mg) & F3 (mg) \\
\hline Glipizide & 5 & 5 & 5 \\
Polyvinylpyrrolidone K30 (PVP K30) (Binder) & 100 & 95 & 90 \\
Corn Starch (Binder and Disintegrating agent) & 115 & 125 & 135 \\
Sodium bicarbonate (Base and effervescent agent) & 140 & 130 & 120 \\
Citric acid (Acidifier) & 40 & 35 & 30 \\
Ascorbic acid (Acidifier) & 50 & 45 & 40 \\
Sodium Saccharine (Sweetener) & 5.5 & 6 & 5 \\
Lactose (Diluent) & 226 & 243 & 260 \\
Magnesium stearate (Lubricant) & 14 & 12 & 10 \\
Sodium Metabisulphite (Stabilizer) & 3.5 & 3 & 4 \\
Congo red cool (Coloring agent) & 1 & 1 & 1 \\
Raspberry flavor (drop) & 1 & 1 & 1 \\
Water (ml) & 0.5 & 0.5 & 0.5 \\
Total wt. & 700 & 700 & 700 \\
\hline
\end{tabular}

\section{c. Tablet preparation}

For every formulation, 60 tablets were prepared by the wet granulation method described by Kristensen and Schaefer, 1987, with a little bit of modification. Firstly, citric acid, saccharine, and ascorbic acid were ground and mixed by mortar and pestle. Then, Glipizide mix with the mixture. The mixture was further added to the slurry made from warm water, Polyvinylpyrrolidone (PVP), and $4 / 5$ starch of the formulation. Then, the wet mass dried for 1 hour at $80^{\circ} \mathrm{C}$. The dried hard mass was further ground and made a granule size passable for 60 mesh size. Then Saccharine, 1/5 starch, sodium metabisulphite, sodium bicarbonate, and magnesium stearate and the granules mixed evenly to form final powder subjected to compression with $13 \mathrm{~mm}$ flat punches of 15 tons Manual Hydraulic Pellet Press. 10.05-ton pressure was applied during tablet compression.

\section{$d$. The angle of repose $(\theta)$ measurement}

A resting angle is the highest possible angle between the powder pile's surface and the horizontal plane. It is indicative of the flow properties and friction force of the loose powder (Nelson, 1955; Thoke et al., 2013). 


$$
\theta=\tan -1(\mathrm{H} / \mathrm{R})
$$

$\theta$, the angle of repose; $\mathrm{H}$, the height of pile; $\mathrm{R}$, the radius of the base of the pile

e. Hausner's ratio

Hausner found that the ratio of tapped density/bulk density related to interparticle friction could be used to predict powder flow properties (Ashish et al., 2011). TheHausner's ratio was calculated by the formula as given below:

$$
\text { Hausner's ratio }=\text { Tapped density } / \text { Bulk density }=\text { Df/Do }
$$

\section{f. Carr's Index}

The indirect method of measuring powder flow from bulk densities, also known as percentage compressibility. Carr's index of each formulation was calculated according to the equation described by Bhowmik et al., 2009, given below:

$$
\text { Carr's index }=[(\mathrm{Df}-\mathrm{Do}) / \mathrm{Df}] \times 100
$$

Where,_Do = bulk density; Df = Tapped density

\section{g. Loss on drying: LOD determination}

Powder equivalent to ten tablets was dried for 4 hours in a desiccator containing silica gel. LOD was calculated as (Rajashree et al., 2010)

$$
\mathrm{LOD}=[(\mathrm{Wi}-\mathrm{Wf}) / \mathrm{Wi}] \times 100 \%
$$

Where Wi and Wf are the initial and final weights of the granules, respectively.

\section{h. Moisture content (MC) determination}

The percent moisture content was calculated using the equation. (Rajashree et al., 2010)

$$
\text { Moisture Content }=[(\mathrm{Wi}-\mathrm{Wf}) / \mathrm{Wf}] \times 100 \%
$$

Where Wi and Wf are the initial and final weights of the granules, respectively.

\section{i. Organoleptic properties (color, smell, taste) test}

Ten healthy volunteers were taken for each formulation to test the color, smell, and taste of the 200ml solution of one effervescent tablet. Informed consent was taken from the volunteers about the test procedure. Color and smell tests were conducted on the nominal terms- Bad, moderate, Good, pleasant. Furthermore, for taste, comments are recorded on Bitter, sour, sour \& sweet, Sweet.

\section{j. Tablet hardness measurement}

Monsanto Hardness Tester measured the hardness of the tablet of each formulation. Hardness or tablet crushing strength is the force required to break a tablet, measured for 10 tablets per formulation in $\mathrm{kg}$.

$$
\text { Hardness average }=\text { Total hardness of all tablets } / \text { No. of tablets }
$$

\section{k. Tablet thickness and diameter determination}

The thickness and diameter of ten tablets for each formulation were evaluated using a calibrated dial caliper described by Srinath et al., 2011.

\section{l. Weight variation determination}

Twenty tablets were taken randomly for each formulation. Then, tablets individually measured the weight of tablets, and each tablet's deviation from the average weight was calculated (Thoke et al., 2013).

\section{m. Friability $(F)$ test}

Roche friabilator was used to assess the friability of the tablet. 10 pre-weighed tablets for each formulation were placed in the friabilator and were subjected to the 100 revolutions. Tables have been polished using a soft muslin cloth and measured. The formula gives the friability $(\mathrm{F})$

$$
\mathrm{F}=[(\mathrm{Wi}-\mathrm{Wf}) / \mathrm{Wi}] \times 100
$$

Where Wi and Wf are the initial and final weights of the tablets, respectively.

\section{n. Measurement of effervescence time}

In a beaker of $200 \mathrm{ml}$ filtered water was placed a single tablet at $20^{\circ} \mathrm{C} \pm 1^{\circ}$. When a clear solution without particles is obtained, effervescence time has been recorded using a stopwatch. The average of five dimensions was calculated to compare the formulations for each formulation. 


\section{o. Determination of effervescent solution $\mathrm{pH}$}

The solution's pH was determined using the pH meter (HI 2211, HANNA) mentioned by Aslani and Fattahi, 2013, after complete dissolution in $200 \mathrm{ml}$ of purified water at $20 \pm 1^{\circ} \mathrm{C}$, immediately after each tablet was dissolved.

\section{p. Tablet's potency determination}

The potency of tablets was determined using a UV spectrophotometer ((Shimadzu UV-1800 spectrophotometer, Shimadzu, Japan) at $\lambda_{\max }=270 \mathrm{~nm}$ as described by Banik et al., 2015.

\section{q. Preparation of standard curve}

Glipizide's mother solution was prepared to dissolve in water with a concentration of $10 \mathrm{mg} / \mathrm{ml}$. This mother solution was diluted serially and made the following concentrations $1 \mathrm{mg} / \mathrm{ml}, 0.2 \mathrm{mg} / \mathrm{ml}, 0.06 \mathrm{mg} / \mathrm{ml}, 0.024 \mathrm{mg} / \mathrm{ml}$ and $0.012 \mathrm{mg} / \mathrm{ml}$. The absorbance was then recorded at a wavelength of $270 \mathrm{~nm}$ by a UV spectrophotometer according to the method given by Banik et al., 2015.

\section{r. Dissolution Studies}

The release rate of glipizide tablet was determined using USP Dissolution Testing Apparatus II (Paddle type). At $37 \pm 0.5^{\circ} \mathrm{C}, 900 \mathrm{ml}$ of phosphate buffer $\mathrm{pH} 6.8$ was used as a dissolution medium. The paddle speed was set at 50 rpm throughout the study. Five $\mathrm{ml}$ of samples were withdrawn at the time interval of 5, 15, 30, 45, 60, and 90 minutes with the replacement of fresh $5 \mathrm{ml}$ medium. The withdrawn $5 \mathrm{ml}$ was subjected to 2 times dilution before taking the absorbance. The samples' absorbance was recorded by UV spectroscopy at $270 \mathrm{~nm}$ using phosphate buffer $\mathrm{pH} 6.8$ as blank. The raw data have been analyzed to identify the quantity and percentage of cumulative drugs released at these times.

\section{Results}

The study highlights the three steps of quality assurance. Firstly, the study focused on granules characterization, which determines the flow of property, adhesiveness, and compressibility. Secondly, it was the characterization of tablets' physical nature, and the last one was on drug content-related parameters.

Table 2. Features of the tablet granules of the formulations (F1, F2, and F3)

\begin{tabular}{llll}
\hline Granules parameter & F1 & F2 & F3 \\
\hline Angle of Repose & $23.12^{0}$ & $27.24^{0}$ & $25.24^{0}$ \\
Hausner ratio & 1.16 & 1.16 & 1.17 \\
Carr's index & $14.325 \%$ & $14.324 \%$ & $14.931 \%$ \\
Loss on Drying & $1.06512 \%$ & $1.2832 \%$ & $1.2832 \%$ \\
Moisture Content & $1.08516 \%$ & $1.3004 \%$ & $1.3004 \%$ \\
\hline
\end{tabular}

The angle of repose of F1 was the least, and the angle for all formulation is less than $30^{\circ}$. Hausner ratio and carr's index for the formulations were almost the same. F3 showed a little bit of variation from the other two. Values of Loss on drying and Moisture content for F3 were smaller than the others in both cases. Whereas the LOD values for F2 and F3 were the same and the same on MC. The features of granules property are represented in table -2 .

Table 3. Physical parameters of tablets of the three formulations (F1, F2, and F3)

\begin{tabular}{llll}
\hline Tablets parameter & F1 & F2 & F3 \\
\hline Colour (Mode) & Pleasant & Pleasant & Pleasant \\
Smell (Mode) & Pleasant & Pleasant & Pleasant \\
Taste (Mode) & Sour & Sour \& Sweet & Sour \\
Thickness (mean in mm) & $4.05 \pm 0.01$ & $4.08 \pm 0.02$ & $4.05 \pm 0.01$ \\
Diameter (mean in mm) & $13 \pm 0$ & $13 \pm 0$ & $13 \pm 0$ \\
Weight variation (mg) & $701.35 \pm 9.931$ & $703.80 \pm 16.732$ & $705.80 \pm 9.217$ \\
Hardness (mean in Kg) & $2.05 \pm 0.093$ & $2.61 \pm 0.086$ & $2.65 \pm 0.203$ \\
Friability & $0.71 \%$ & $0.73 \%$ & $0.69 \%$ \\
Disintegration time (mean in seconds) & 105 & 90 & 100 \\
pH of the effervescent solution & $7.0 \pm 0.02$ & $7.0 \pm 0.02$ & $7.0 \pm 0.02$ \\
\hline
\end{tabular}


The model on the volunteers' comment on the color and smell of three formulations was the same, but the mode of taste for F2 was sour and sweet, whereas, for F1 and F3, it was sour. The mean thickness of F1 and F2 was 4.05 $\mathrm{mm}$, and the mean of F2 was 4.08. The mean diameter of the formulations was 13 . The highest mean weight of 20 tablets was for F3, but the standard deviation was the highest for F2. The mean hardness of F1 and F3 was around $2.60 \mathrm{~kg}$, but the hardness of F1 was $2.05 \mathrm{~kg}$. The formulations showed a friability of around $0.7 \%$. However, the mean disintegration time showed few deviations depending on the formulation. This time of F1, F2, and F3 was $105 \mathrm{~s}, 90 \mathrm{~s}$, and 100s. The last physical parameter was to determine the $\mathrm{pH}$ of the effervescent solution. In all of the cases, the values were $7.0 \pm 02$. The physical parameter of different formulations of Glipizide $5 \mathrm{mg}$ tablets are represented in Tabe- 3 .

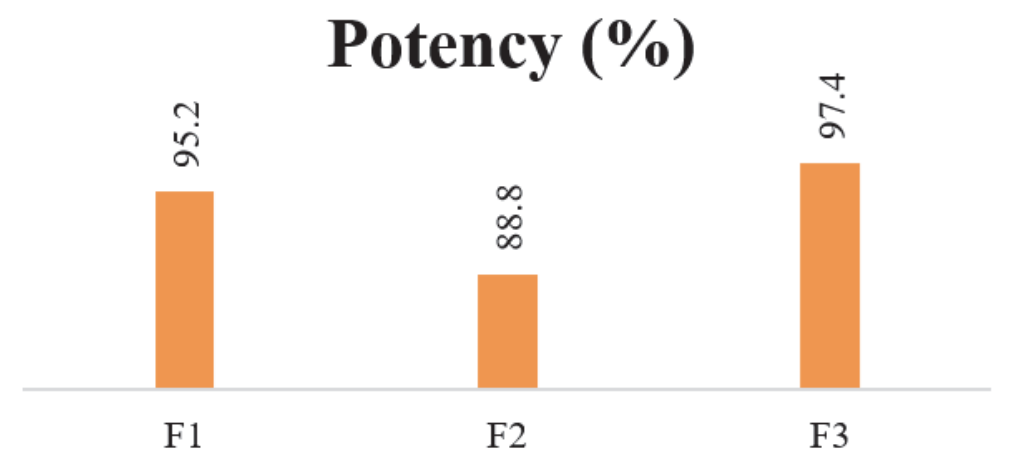

Figure 1. The potency of effervescent tablets for the three formulations

The highest potency, 97.4\%, was explored by F3 among the three formulations, as mentioned in Fig 1. Moreover, the lowest potency was found for F2, with a value of $88.8 \%$. According to Fig 2 , the regression line was very close to 1 , indicating the linear relationship of absorbance with concentrations.

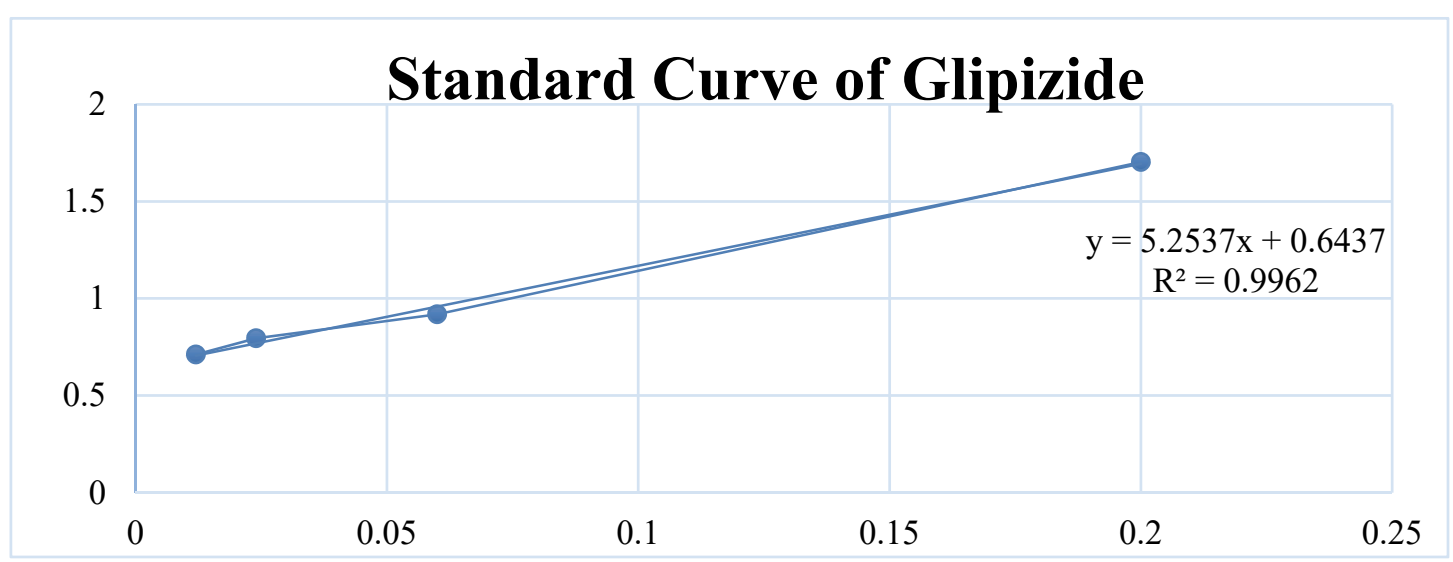

Figure 2. Standard Dose-response curve of Glipizide plotting absorbance against concentration.

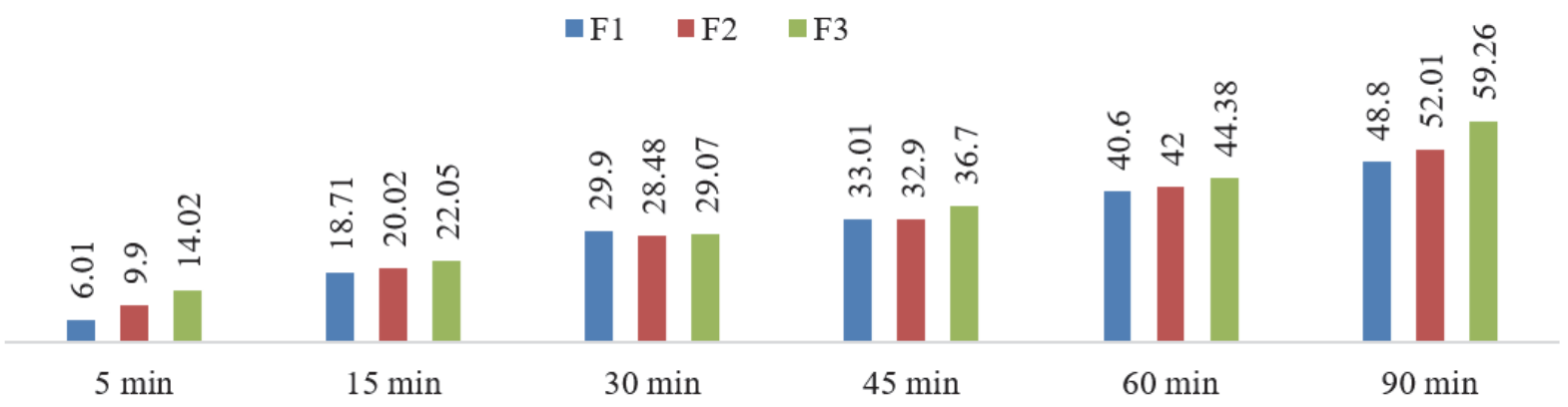

Figure 3. The cumulative percentage of drug dissolution from the tablets of the three formulations with different time intervals 
The extent of drug dissolution increased with time for the formulations, as mentioned in Fig 3 . The count started from 5 minutes of analysis and ran up to 90 minutes. At 5 minutes, only F3 showed dissolution near $15 \%$. In the last point of time, the cumulative amounts of the dissolved drug for F1, F2, and F3 were $48.8 \%, 52.01 \%$, and $59.26 \%$, respectively. F1 showed the minimum values at the most points in time, whereas F3 exhibit the highest cumulative dissolution among the three.

\section{Discussions}

Most of the oral conventional tablets and capsules are formulated to be chewed or swallowed. Despite the attractiveness of effervescent dosage forms, $5 \mathrm{mg}$ of Glipizide effervescent tablet is not available. Since the drug is poorly water-soluble and has better tolerability by patients, we decided to formulate three effervescent tablets.

The repose angles of all three formulations were smaller than 30 , which means the 'very free-flowing' nature of the granules (Al-Hashemi et al., 2018). Hausner ratio 1.12-1.18 and Carrs index 11-15 indicate the excellent flow of powder material (Kaleem et al., 2020). The values of both tests for the formulations covered the rages. So, the prepared granules carry the nature of suitable flow property, but we cannot say it excellent. Furthermore, moisture content below $2.5 \%$ proves the free-flowing nature of granules (Thapa et al., 2017). So, the prepared granules' $\mathrm{LOD}$ and $\mathrm{MC}$ were maintained around $1.3 \%$ to adjust flow property and reducing the risk of moisture absorption by hygroscopic excipients (ascorbic acid, citric acid) used in tablet formulation.

The effervescent solution's color and flavor depend on the amount and types of coloring and flavoring agents. Even there should have an adjustment of color with flavor. The reddish solution with raspberry favor in a specific concentration for formulations proved pleasant to the volunteer. The effervescent solution's tastes were determined by the acids, base, and sweetening agent used in the formulations. Formulation F2 tasted sour and sweet, which may be better than the other two formulations' sour test. Though the formulations' hardness was less than 3 , the determined friability was less than $1 \%$.

What is more, the effervescent time and effervescent solution $\mathrm{pH}$ of all formulations were reasonably acceptable for the dosage form (Aslani and Jahangiri, 2013). F1 showed the least hardness. This may happen to use a more disintegrating agent (Corn starch) and lubricating substance (Magnesium stearate) than the others. However, the $\mathrm{MC}$ and LOD of F1 were lower than the others; it might affect hardness.

Assay on drug content in tablets, F2 failed to meet the USP and BP specifications, it may reason behind its more considerable weight variability. The other two formulations are successful in passing the USP specification under the range (90\%-100\%). After confirmation of dose-response relation with UV absorbance, the drug release pattern was conducted. Glipizide is a poorly water-soluble drug, so the dissolution of the drug into assay media was probable to be very low. After one and a half hours, F3 exhibited the highest cumulative value of dissolution with 59.2\%. The least amount of binder PVP in F3 might contribute to its maximum drug release. The releases and dissolution of the drug from the three formulations were more than conventional tablets and the floating effervescent tablets (Nanjwade et al., 2012; Ramabargavi et al., 2013). Despite it raises a question, is there any real therapeutic advantage over other conventional glipizide tablets? Effervescent dosage release starts with a physical breakdown of the whole dosage form. Although molecular interaction of the drug with water is negligible, drug molecules turn to a media dispersion system. This dispersion may cause better dissolution and absorption, having high permeability through the biological membrane (Jamzad and Fassihi, 2006). This study has successfully developed an effervescent tablet of Glipizide $5 \mathrm{mg}$ that can disintegrate within two minutes, highly elegant to the patient with its taste and appearance, and meet other tableting parameters. Patients can quickly adopt this formulation for prolonged anti-diabetic therapy.

\section{Conclusions}

The study explored the substantial relationship between compositions and results on the test parameters. Effervescent tablets offer attractive aesthetic values and enhance the bioavailability of drugs when compared to conventional tablets. This effervescent formulation will be a more attractive option for diabetic patients, especially for patients with prolonged anti-diabetic therapy, and pharmaceutical companies worldwide can adopt this formulation after a successful bioequivalence study to evaluate the effectiveness of the prepared effervescent tablets.

\section{Acknowledgments}

The authors are grateful to Beximco Pharmaceutical Ltd., Bangladesh, to provide the drug sample glipizide and be thankful to the Department of Applied Chemistry and Chemical Engineering, Noakhali Science and Technology University, Noakhali, for their technical supports. 


\section{References}

Abdelmoneim, A. S., Hasenbank, S. E., \& Seubert, J. M. (2012). Variations in tissue selectivity amongst insulin secretagogues: A systematic review. Diab Obes Metab, 14(2), 130-138. https://doi.org/10.1111/j.14631326.2011.01496.x

Agrawal, A. G., Kumar, A., \& Gide P. S. (2015). Self emulsifying drug delivery system for enhanced solubility and dissolution of Glipizide. Colloid Surf B, 126, 553-560. https://doi.org/10.1016/j.colsurfb.2014.11.022

Agyilirah, G. A., Green, M., \& Banker, G. S. (1991). Evaluation of the gastric retention properties of a cross-linked polymer-coated tablet versus those of a non-disintegrating tablet. International Journal of Pharmaceutics, 75(2-3), 241-247. https://doi.org/10.1016/0378-5173(91)90198-W

Al-Hashemi, H. M. B., \& Al-Amoudi, O. S. B. (2018). A review on the angle of repose of granular materials. Powder Technology, 330, 397-417. https://doi.org/10.1016/j.powtec.2018.02.003

Ashish, P., Mishra, P., Main, P., Harsoliya, M., \& Agrawal, S. (2011). A review on-recent advancement in the development of rapid disintegrating tablet. Int J Life Sci Pharm Res, 1, 7-16.

Aslani, A., \& Fattahi, F. (2013). Formulation, characterization, and physicochemical evaluation of potassium citrate effervescent tablets. Advanced Pharmaceutical Bulletin, 3(1), 217. https://doi.org/10.5681/apb.2013.036

Aslani, A., \& Jahangiri, H. (2013). Formulation, characterization, and physicochemical evaluation of ranitidine effervescent tablets. Advanced pharmaceutical bulletin, 3(2), 315. https://doi.org/10.5681/apb.2013.051

Banik, S., Karmakar, P., \& Miah, M. A. H. (2015). Development and validation of a UV-spectrophotometric method for determination of vildagliptin and linagliptin in bulk and pharmaceutical dosage forms. Bangladesh Pharmaceutical Journal, 18(2), 163-168. https://doi.org/10.3329/bpj.v18i2.24316

Bhowmik, D., Chiranjib, B, Krishnakanth, Pankaj, R., \& Chandira M. (2009). Fast Dissolving Tablet: An Overview. Journal of Chemical and Pharmaceutical Research, 163-177.

Bösenberg, L. H., \& Van Zyl, D. G. (2008). The mechanism of action of oral anti-diabetic drugs: a review of recent literature. Journal of Endocrinology, Metabolism and Diabetes of South Africa, 13(3), 80-88. Https://doi.org/10.1080/22201009.2008.10872177

Harald, S. (2003). Effervescent dosage manufacturing. Pharmaceutical Technology Europe, 25-28.

Isaac, J., Kaity, S., Ganguly, S., (2013). Microwave-induced solid dispersion technology to improve bioavailability of Glipizide. J Pharm Pharmcol, 65(2), 219-229. https://doi.org/10.1111/j.2042-7158.2012.01595.x

Jamzad, S., \& Fassihi, R. (2006). Development of a controlled release low dose class II drug-Glipizide. International Journal of Pharmaceutics, 312(1-2), 24-32. https://doi.org/10.1016/j.ijpharm.2005.12.037

Josep, M., Suñé-Negre, Pérez-Lozano, P., Roig, M., Fuster, R., ...Ticó, J. R. (2011). Optimization of parameters of the SeDeM Diagram Expert System: Hausner index (IH) and relative humidity (\%RH), European Journal of Pharmaceutics and Biopharmaceutics, 79(2), 464-472. https://doi.org/10.1016/j.ejpb.2011.04.002

Kaleem, M. A., Alam, M. Z., Khan, M., Jaffery, S. H. I., \& Rashid, B. (2020). An experimental investigation on accuracy of Hausner Ratio and Carr Index of powders in additive manufacturing processes. Metal Powder Report. https://doi.org/10.1016/j.mprp.2020.06.061

Khan, A., Iqbal, Z., Rehman, Z., Nasir, F., Khan, A., Ismail, M., \& Mohammad, A. (2014). Application of SeDeM Expert system in formulation development of effervescent tablets by direct compression. Saudi Pharmaceutical Journal, 22(5), 433-444. https://doi.org/10.1016/j.jsps.2013.07.002

Kristensen, H. G., \& Schaefer, T. (1987). Granulation: A review on pharmaceutical wet-granulation. Drug Development and Industrial Pharmacy, 13(4-5), 803-872. https://doi.org/10.3109/03639048709105217

Lieberman, H. A., Lachman, L., \& Schwartz, J. B. (Eds.). (1980). Pharmaceutical dosage forms: Tablets (Vol. 1, pp. 109-124). M. Dekker.

Mohammed, K. A. B., Ibrahim, H. K., \& Ghorab, M. M. (2016). Effervescent tablet formulation for enhanced patient compliance and the therapeutic effect of risperidone. Drug Delivery, 23(1), $297-306$. https://doi.org/10.3109/10717544.2014.912693

Nanjwade, B. K., Adichwal, S. A., Nanjwade, V. K., Gaikwad, K. R., Thakare, S. A., \& Manvi, F. V. (2012). Development and evaluation of gastroretentive floating tablets of Glipizide based on effervescent technology. J Drug Metab Toxicol, 3(3), 1-5. https://doi.org/10.4172/2157-7609.1000121 
Nauck, M., Meininger, G., Sheng, D. O., Terranella, L., Stein, P. P., \& Sitagliptin Study 024 Group. (2007). Efficacy and safety of the dipeptidyl peptidase-4 inhibitor, sitagliptin, compared with the sulfonylurea, Glipizide, in patients with type 2 diabetes inadequately controlled on metformin alone: a randomized, doubleblind, non-inferiority trial. Diabetes, Obesity and Metabolism, 9(2), 194-205. https://doi.org/10.1111/j.14631326.2006.00704.x

Nelson, E. (1955). Measurement of the repose angle of a tablet granulation. Journal of the American Pharmaceutical Association, 44(7), 435-437. https://doi.org/10.1002/jps.3030440714

Osei-Yeboah, F., Minglun Zhang, M., Feng Y., \& Sun C. C. (2014), A Formulation Strategy for Solving the Overgranulation Problem in High Shear Wet Granulation, Journal of Pharmaceutical Sciences, 103(8), 24342440. https://doi.org/10.1002/jps.24066

Östman, J., Christenson, I., Jansson, B., \& Weiner, L. (1981). The anti-diabetic effect and pharmacokinetic properties of Glipizide: comparison of a single dose with divided dose regime. Acta Medica Scandinavica, 210(1-6), 173-180. https://doi.org/10.1111/j.0954-6820.1981.tb09796.x

Patel, J. K., Patel, R. P., Amin, A. F., \& Patel, M. M. (2005). Formulation and evaluation of mucoadhesive glipizide microspheres. AAps PharmSciTech, 6(1), E49-E55. https://doi.org/10.1208/pt060110

Rajashree, M., Yellanki, S. K., Patil, B. R., \& Manvi, F. V. (2010). Development and evaluation of floating matrix tablets of Riboflavin. International Journal of PharmTech Research, 2(2), 1439-1445.

Ramabargavi, J. L., Pochaiah, B., Meher, C., Kishan, S., \& Srujana, B. (2013). Formulation and in vitro evaluation of gastroretentive floating tablets of Glipizide. J Chem. Pharm Res, 5(2), 82-96.

Saleh, S. I., Boymond, C., \& Stamm, A. (1988) Preparation of direct compressible effervescent components: spraydried sodium bicarbonate. International Journal of Pharmaceutics, 45(1-2), 19-26. https://doi.org/10.1016/0378-5173(88)90030-0

Srinath, K. R., Chowdary, C. P., Palanisamy, P., Krishna, A., \& Aparna, S. (2011). Formulation and evaluation of effervescent tablets of paracetamol. Int J Pharm Res Dev, 3(3), 76-104.

Thapa, P., Lee, A. R., Choi, D. H., \& Jeong, S. H. (2017). Effects of moisture content and compression pressure of various deforming granules on the physical properties of tablets. Powder Technology, 310, 92-102. https://doi.org/10.1016/j.powtec.2017.01.021

Thoke, S. B., Sharma, Y. P., Rawat, S. S., \& Nangude, S. L. (2013). Formulation development \& evaluation of effervescent tablet of Alendronate sodium with vitamin D3. Journal of Drug Delivery and Therapeutics, 3(5), 65-74. https://doi.org/10.22270/jddt.v3i5.623

Tsume, Y., Langguth, P., \& Garciaarieta, A. (2012). In silico prediction of drug dissolution and absorption with variation in intestinal $\mathrm{pH}$ for BCS class II weak acid drugs: Ibuprofen and ketoprofen. Biopharm Drug Dispos, 33(7), 366-377. https://doi.org/10.1002/bdd.1800

Verma, R. K., \& Garg, S. (2005). Selection of excipients for extended release formulations of Glipizide through drug-excipient compatibility testing. J Pharmaceut Biomed, 38(4), 633-644. https://doi.org/10.1016/j.jpba.2005.02.026

\section{Copyrights}

Copyright for this article is retained by the author(s), with first publication rights granted to the journal.

This is an open-access article distributed under the terms and conditions of the Creative Commons Attribution license (http://creativecommons.org/licenses/by/4.0/). 